\title{
Competency profiles for lean professionals - an international perspective
}

This is the author's version of a work that was accepted for publication in the following source:

Kregel, I., Ogonek, N. and Matthies, B. (2019), "Competency Profiles for Lean Professionals - An International Perspective", International Journal of Productivity and Performance Management, Vol. 68 No. 2, 423-446.

(C) Emerald Publishing Limited 2019

Notice:

Changes introduced as a result of publishing processes such as copy-editing and formatting may not be reflected in this document. For a definitive version of this work, please refer to the published source:

https://doi.org/10.1108/IJPPM-09-2017-0237 


\section{Competency Profiles for Lean Professionals - An International Perspective}

Purpose: Requirements for business improvement professionals depend on different job characteristics. By focusing on lean management, the paper has a twofold aim: First, to provide a comprehensive conceptualisation of competencies relevant for lean professionals by comparing them to an existing project management competency framework and second, to identify their similarities and differences in three different analysed countries.

Design/methodology/approach: This paper investigates 2,701 online published job advertisements in the USA, UK, and Germany by means of a content analysis to compare and contrast the respective job profiles.

Findings: Main findings are similarities and differences in the specification and perception of lean professional's roles among the three countries. Strikingly, four out of eight considered competency categories comprise $74 \%$ of the profiles' most relevant keywords. Additionally, with the help of a latent semantic analysis, 16 specific competencies can be summarised in a Lean Professional's Competency Taxonomy.

Research limitations/implications: The collected data only represents a snapshot of lean professionals' advertisements. Also, text mining results from job profiles could largely differ from other techniques like recruiter interviews or company surveys. Further research could use different methods or combine them to construct a more complete model.

Practical implications: Lean education and training as well as the respective candidate selection processes can benefit from these study's results.

Originality/value: Requirements and job contents for lean professionals have not been empirically researched on a comparable in-depth level before, even though their expertise is in high demand in any kind of business sector.

Keywords: Lean Management; Competencies; Job Profile; Content Analysis 


\section{$1 \quad$ Introduction}

Lean management has been one of the most successful business process improvement methodologies during the last years and decades (Lewis, 2000; Fullerton and McWatters, 2001; Liker and Morgan, 2006; Negrão et al., 2017). Despite its wide application, the specific skills and competencies needed for lean professionals have not been extensively researched. As there is no common standard, lean trainings largely differ in length and covered topics between organisations and sectors (Karlsson and Åhlström, 1996; Emiliani, 2003). Despite the popularity of lean, struggles and failures are very common. They include "human"-oriented problem areas like leadership, employee and lack of training and education (Achanga et al., 2006; Albliwi et al., 2014). This study summarises commonly required competencies of lean professionals by using data from job postings as a market perspective. To categorise needed competencies of lean professionals, a first step was to analyse competency frameworks of related fields.

Several studies already analyse knowledge and skill requirements for the field of general project management (Pant and Baroudi, 2008; Skulmoski and Hartman, 2010). As part of the business process management discipline (Paim et al., 2008; Sidorova and Isik, 2010), lean management also represents one of the domains of information systems (Hicks, 2007). Although there are studies about general competencies of information systems students and professionals (Tang et al., 2001; Lee et al., 1995; Nelson, 1991), the specifics of lean management are not examined in detail. Therefore, this study focuses on the needed competencies of lean professionals like lean project managers and trainers.

The exploration of competency requirements is a common and widespread research field (Lawler, 1994; Todd et al., 1995). In the context of business process management, several competency studies can be found. For example, Lohmann and Zur Muehlen (2015) as well as Müller et al. (2016) developed competency typologies for business process management professionals. Kettenbohrer et al. (2016) explored the influence of perceived job characteristics on employees' process orientation. Gorbacheva et al. (2016), as another example, examined gender issues in business process management competency supply. There has been research about required skills for project managers in general (Ahsan et al., 2013; El-Sabaa, 2001; Pettersen, 1991) and six sigma project managers (Black and McGlashan, 2006; Antony et al., 2007; Antony and Karaminas, 2016), but not specifically for lean project managers or lean professionals. Therefore, the purpose of this study is to close this research gap and to explore the specific competency requirements in the field of lean management. This is a first attempt to categorise the needed competencies in this field. By making use of an existing project management framework developed by Brill et al. (2006), the degree of conformance between the two job profiles can be analysed and future research could focus on the creation of a lean professional's competency framework, based on several sources. 
In summary, the following research question is addressed in this paper: Which competencies characterise the job requirements of lean management professionals in the USA, UK, and Germany?

The exploration of lean management competencies is based on a computer-aided content analysis of lean management-related job advertisements $(N=2,071)$. A categorisation of keywords and a latent semantic analysis were performed to summarise the competency areas commonly described in such job advertisements. As a result, this study provides statements about the relevance of eight from the total nine different competency categories as well as a comprehensive conceptualisation of specific core competencies relevant in the field of lean management. The term core competency in this study refers to the lean manager's most critical individual competencies, necessary to meet the job's requirements.

This paper is structured as follows: Section two addresses the theoretical foundations of professional competencies. Section three introduces the methodology of the study, describing the used computeraided content analysis techniques as well as the underlying database of job advertisements. Section four presents the results of the study. A discussion of the findings will be provided in section five. Finally, section six will deal with the implications and limitations of this study.

\section{Research Background}

\subsection{Competency requirements in business process management and project management}

Competencies form the key resource in every organisational context, because people with the right competencies who are able to perform the required tasks are needed. This is why the identification and description of specific work-related competencies has become a popular means for job advertisements and measurements in academia as well as in practice. The term competency refers to the combination of an individual's work-related knowledge, skills and abilities (Nordhaug, 1993). The identification of success factors in the field of business process management (BPM) has also been extensively researched. Ranging from an early merely technical perspective, ascribing organisational success primarily to the smart use of information technology (IT) (e.g. Altinkemer et al., 2011; Dumas, 2013) to a more comprehensive approach, also acknowledging the importance of the human variable and its capabilities as decisive influence factor in the field (e.g. De Bruin and Rosemann, 2007; Trkman, 2010; Rosemann and vom Brocke, 2015). In line with this, the identification of the right competencies has gained importance. As previously mentioned, Gorbacheva et al. (2016) identify twelve BPM competency categories by means of a text mining technique, analysing more than 10,000 job profiles of BPM professionals published on LinkedIn. These competency groups, however, are rather abstract since they are not specified down to concrete competencies. Another framework, especially designed for project managers in the UK industry, is provided by the Association for Project Management (APM, 2015). 
This framework breaks a total set of 27 required competencies down to different levels in terms of the skills that are to be applied and the knowledge that is necessary for it. These competencies are described on a very detailed level, which makes it hard - for the purpose of this study - to match them to the specific job profiles. Also, distinctions between application and knowledge are hardly specifically defined in the job advertisements.

This study focuses on job advertisements of "lean professionals" who are specialised business process professionals in the field of lean management. The term "lean professional" is considered to be generic for a range of related job titles, such as for example, "lean manager", "lean consultant", "lean specialist", or "lean six sigma expert". Müller et al. (2016) in their text mining analysis identify a group of Business Process Improvement Managers, representing terms of "management and problem-solving subcategories [...] management competencies are 'manag', 'process', 'busi', 'project', 'lead' and 'organ', indicating a need for process and project management competencies [...] problem-solving competencies include 'improve', 'lean', 'six' and 'sigma', which refer to the lean and six sigma process improvement methodologies. The titles of high-loading job ads confirm this proposition (e.g. Business Process Excellence Manager, Lean Consultant, Director Business Process Improvement).” The postulate of the smart use of IT for successful business process management nowadays becomes even more important, due to the pervasiveness of IT. Every employee, especially those working in knowledge intensive jobs, will need to be equipped with a certain degree of digital competencies to be able to work in the digital age (Murawski and Bick, 2017). Those competencies can be referred to as " $[\ldots]$ the ability to adopt and use new or existing information technology to analyse, select and critically evaluate digital information in order to investigate and solve work-related problems and develop a collaborative knowledge body while engaging in organizational practices within a specific organizational context" (Vieru, 2015, p. 6718).

\subsection{Frameworks for the classification of competencies}

In search of a suitable framework for the categorisation of lean professional's competencies, the term's comprehension was broadened and opened for frameworks of other job profiles. There is a plethora of different job-specific competency frameworks, e.g. for ICT professionals, a European e-Competence Framework for ICT Professionals in all industry sectors was developed by the European Committee for Standardisation (2018). The company $3 \mathrm{M}$ developed a leadership competency model for internal use that should be of help in assessment, development, and succession (Alldredge and Nilan, 2000). Another framework that ranges across different job profiles is the Occupational Information Network (O*NET), developed by the U.S. Department of Labor/Employment and Training (Usdol/Eta, 2018). This framework combines six different categories including both, activity and task-related characteristics as 
well as abilities and skills. Three of those categories focus on the employee-related dimensions (worker characteristics, worker requirements and experience requirements), the other three are job-related dimensions (occupational requirements, workforce characteristics and occupation-specific information). Although representing a very hands-on tool with a standardised set of characteristics, this framework was not considered, given its abundance of information as well as the specific research interest in the employees' competencies and their experience, which primarily concerns roughly half of the six offered dimensions, i.e. the employee-related dimensions.

Change management represents another influence for lean competencies. As business process improvement requires changes of processes and employee's behaviour (Kotter, 1996), this topic was analysed for potential competency classification, too. Kettinger et al. (1997) describe a Business Process Change Model, consisting of the five subsystems business processes, structure, management, information \& technology, and people. Even if competency aspects can be found in several of these subsystems, the competencies are not analysed in detail. Therefore, this framework does not fit the research's purpose. Further research addresses needed values and behaviours of effective lean managers (van Dun and Wilderom, 2016; van Dun et al., 2017). Their results show the importance of different indicators of self-transcendence and openness to change, but do not deliver change competency frameworks suited for the analysis of job profiles. The eight clusters of change management competencies of Higgs and Rowland (2000) strongly focus on details of change management and do not cover the work of actual process change experts like lean professionals. Another framework, the competency model of Vakola et al. (2007) includes the areas of interpersonal excellence, project operations management, business sense decision making, sales management, and people management. Finally, these competency areas show some potential for categorising the text mining results. After consulting with lean experts though, the search was broadened to find an even better fitting framework, as many typical lean professional's competencies could not be considered in the analysed frameworks so far.

Because of the above-mentioned classification of business process improvement managers, frameworks for project managers were analysed, since the job of a lean professional is oftentimes highly projectdriven (Hines et al., 2004; Shah and Ward, 2007; Pettersen, 2009). Besides problem-solving competencies, also profound project management competencies are required. They are more specific in character and also demand social skills, due to the work with a variety of different stakeholders involved in the process improvement projects (Müller and Turner, 2010; Skulmoski and Hartman, 2010; Fisher, 2011). After evaluating the APM Competence Framework (Association for Project Management, 2015) as too detailed for the research purpose, the one developed by Brill et al. (2006) was chosen. Their 
framework for the effective project manager consists of nine categories, which are summarised in Table 1 and described in the following.

\begin{tabular}{|l|l|}
\hline Category No. & Competency Name \\
\hline 1 & (Problem-Solving Expertise) \\
\hline 2 & Leadership Expertise \\
\hline 3 & Context Knowledge \\
\hline 4 & Analytical Expertise \\
\hline 5 & People Expertise \\
\hline 6 & Communication Expertise \\
\hline 7 & Personal Characteristics \\
\hline 8 & Project Administration Expertise \\
\hline 9 & Tools Expertise \\
\hline
\end{tabular}

Table 1. Project Manager Competency Categories by Brill et al. (2006)

The first category problem-solving expertise contains competencies that range from the ability to recognise a problem to the management of risk and crises to the application of the right methods. This general category is at the core of lean projects. As problem solving in general and by using lean methods could not be differentiated clearly enough, this category was jointly considered with category no. 4: analytical expertise. This category comprises capturing the situation, prioritising and using the right methodologies, which also is a core competency of a lean professional. The second category leadership expertise encompasses characteristics like delegation, coaching, teaching and mentoring as well as diplomacy and persuasiveness, amongst others. Category 3 comprises context knowledge, i.e. all knowledge that is not purely project-oriented but helps to make more adequate estimates. This knowledge refers to stakeholder- and industry knowledge and knowledge of related fields as well as awareness of the goals, mission and scope of the project. Additionally, work experience and educational degrees were sorted into this category since they provide a better understanding of the project. People expertise focuses on mutual understanding, consensus building and resolving conflicts. In category 6 , all competency characteristics are listed that either deal with communication as a tool in terms of written and verbal communication/presentation skills or in terms of (foreign) language skills, i.e. sufficient knowledge of at least one or more languages. Personal characteristics (7) deal with all personality traits that a person may have like e.g. openness, fairness, honesty, just to name a few. Project administration expertise includes all mandatory steps to manage a project, from creating a plan, to the management of time and resources and the monitoring of budgets. The last category tools expertise is about having computer skills and using specific (lean) tools. For this aspect, tools were distinguished from broad lean 
methodology terms like "continuous improvement management" or "lean manufacturing", which are listed under analytical expertise.

\subsection{Competency requirements in lean management}

As previously introduced, this work analyses the aspect of process improvement in business process management in detail. Studies like Müller et al. (2016) formed the role of a business process improvement manager in general, without distinguishing between different improvement methods or other factors. First data samples in this direction showed a frequent occurrence of six sigma terms. This quality management methodology (Schroeder et al., 2008) is part of many process improvement job profiles but not necessarily always connected to the role of lean professionals (Hines et al., 2004). The methodology of six sigma is not only relevant to the production industry, but also to services and administration (Antony, 2006; Heckl et al., 2010). The role of different six sigma belts (Antony and Karaminas, 2016) as well as the importance of project leadership experience for the success of six sigma projects (Easton and Rosenzweig, 2012) have been researched in much more detail than lean management competencies and trainings (Ramadas and Satish, 2018; Vlachos and Siachou, 2018). Since 2011, two ISO standards describe the six sigma methodology and tools as well as roles and responsibilities. For example, they include minimum competency requirements and recommended minimum course durations to set training standards for different belt certifications (International Standards Office, 2011a; 2011b). Compared to this extensive literature in the field of a related business process improvement methodology, the research of lean competencies still has to be expanded.

The concept of lean six sigma combines philosophical elements, methods and tools from six sigma and lean management (Albliwi et al., 2015; Näslund, 2008). The degree of application of the individual parts differs from company to company and depends on process and organisation characteristics as well as the operations strategy (Drohomeretski et al., 2013). Opposing the six sigma standards, this study explicitly focuses on the less standardised job roles of lean professionals, so six sigma and lean six sigma should not be centre of the analysis. As the first results, only including "lean" turned out not to be sufficient. Therefore, the search was extended to the concept of "continuous improvement". Both concepts are closely related to each other and originate from the same field of activity. Lean Management or lean thinking can be seen as a philosophy (Bhasin and Burcher, 2006) to eliminate "waste" in processes (Thürer et al., 2017) as well as to analyse and optimise them regarding the creation of value to the customers (Hines et al., 2004). Continuous improvement relating to lean is equated with the concept of Kaizen created by Masaaki Imai (Imai, 1986; Recht and Wilderom, 1998). Brunet and New (2003, p. 1428) formulated the concept of Kaizen "to consist of pervasive and continual activities, outside the contributor's explicit contractual roles, to identify and achieve outcomes he believes 
contribute to the organizational goals". Continuous improvement has also been identified to be part of the core values of BPM culture (vom Brocke and Sinnl, 2011; Schmiedel et al., 2013, 2014). Therefore, an important goal of continuous improvement is to achieve a high commitment lean culture embedding work on processes in the daily routines (Treville and Antonakis, 2006; Angelis et al., 2011; Bortolotti et al., 2015).

Companies apply process orientation and continuous improvement initiatives to achieve competitive advantage (Bessant et al., 2001; Kohlbacher and Reijers, 2013; Ittner and Larcker, 1997). As a lean professional, creating and extending the capability for continuous improvement is part of their role within companies (Bessant and Francis, 1999; Haikonen et al., 2004; Parry et al., 2010). Assessing and developing the needed skills of the employees and training them in process improvement methods are core characteristics of lean deployments and successful initiatives (Lee, 2004; Cachay and Abele, 2012; Needy et al., 2015).

\subsection{Cultural influence on competency levels}

In order to analyse the possibly unveiling differences between lean management in the three countries, it is necessary to look into different cultural conceptions. Two studies are to be emphasized in this context. Hofstede and Hofstede (2005) analysed in how far the work of corporations worldwide are subject to cultural influences. They established five cultural dimensions for this purpose: power distance, individualism/collectivism, masculinity/femininity, uncertainty avoidance and long-term/short-term orientation. Within these dimensions, the different countries receive scores from zero to 100, according to their orientation, depicting similarities and differences. In a similar vein, the research done by Trompenaars and Hampden-Turner (2000) offers guidance for managers on how to navigate in an international business environment. Similar to Hofstede and Hofstede (2005), they compare different countries based on six different indicators: universalism versus particularism, individualism versus communitarianism, neutral versus emotional, specific versus diffuse and achievement versus ascription.

\section{$3 \quad$ Research Process and Methodology}

\subsection{Research Process}

The research process of this study is roughly structured according to the CRISP-DM (Cross-Industry Process for Data Mining) framework (Shearer, 2000) and covers the phases research question, data collection, data preparation, data analysis and modelling \& evaluation (see Figure 1). In the first phase, the research gap and question were specified based on a literature review (see Section 1 and 2). In addition, a founding framework (Brill et al., 2006) for the lean competency assessment and modelling 
was defined. The phases of data collection and data preparation cover the compilation of 2,071 job advertisements and the pre-processing of the textual database into an analysable format (see Section 3.3). In the next phase, the prepared textual database was analysed by means of two complementary text analyses (see Section 3.2 as well as Sections 3.4 and 3.5). In the final phase, the results of the text analyses were used to model and evaluate a competency taxonomy for lean professionals (see Section $4.2)$.

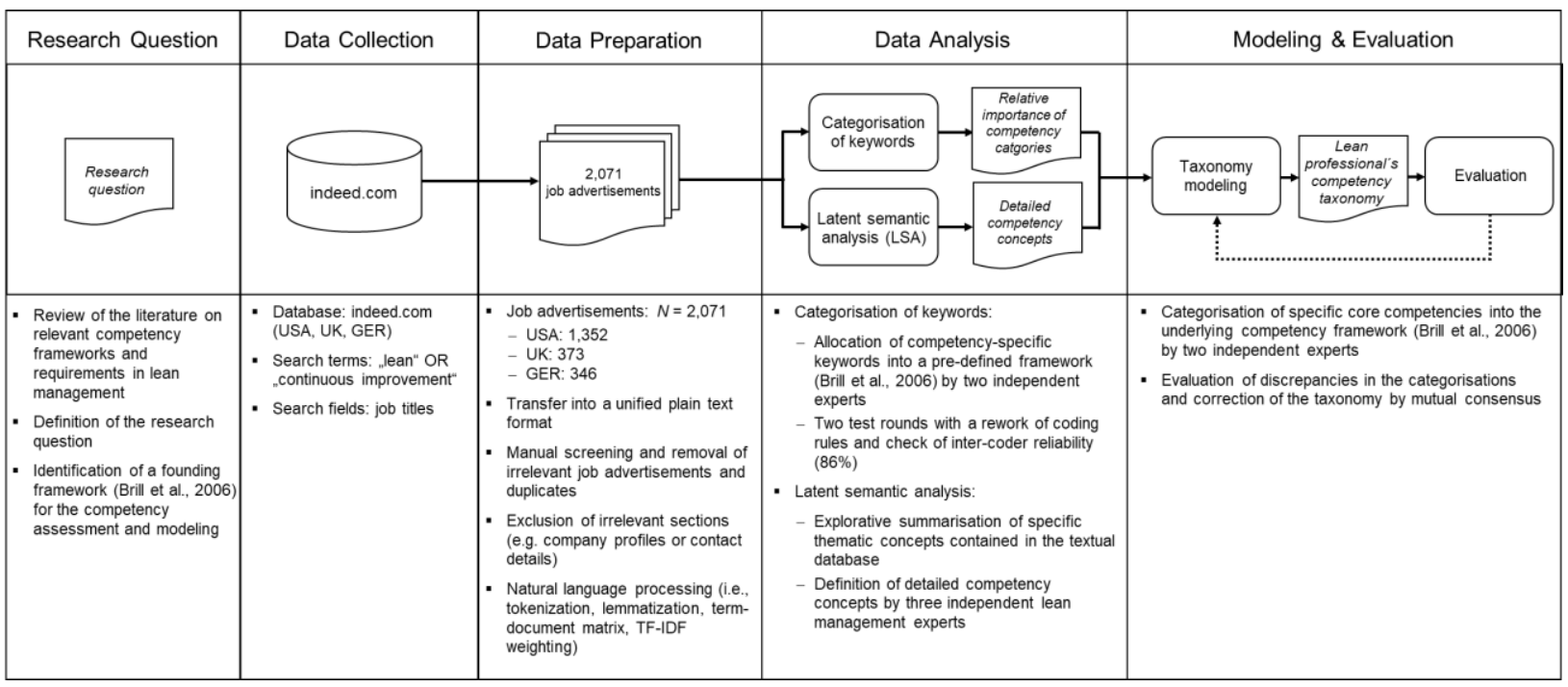

Figure 1. Applied Research Process

\subsection{Methodology}

The exploration of lean management competencies is grounded in a content analysis of lean management-related job advertisements. Content analysis can be understood as an "empirically grounded method" (Krippendorff, 2013, p. 1) which aims at the systematic, objective, and quantitative exploration of the manifest content in textual communication (Berelson, 1952, p. 18). However, manual content analyses quickly reach their capacity limits when analysing large volumes of texts (Indulska et al., 2012, p. 49). In order to explore lean management competencies described in large collections of job advertisements, this study is therefore based on two computer-aided content analysis techniques that provide a semi-automated summary of the thematic structure in job advertisements: (I) categorisation of keywords and (II) latent semantic analysis (LSA).

I. The categorisation of keywords includes the identification and allocation of competencyspecific words or word combinations into a pre-defined framework with relevant competency categories (see Brill et al., 2006). The underlying assumption in this process is that the volume of keywords not only reflects the distribution but also the relevance of the respective topic 
(Weber, 1990). Therefore, a subsequent counting of competency-specific keywords permits quantitative statements about the relevance of competency categories in the examined job advertisements.

II. The latent semantic analysis (LSA) is a semi-automated content analysis technique that allows the explorative summarisation of large textual databases (see, e.g. Landauer et al., 1998). LSA applies statistical analyses in order to extract frequently used word patterns (i.e., correlating words regularly occurring together) which can be interpreted as specific topics contained in the underlying textual database. It is therefore an advantageous means for the exploration and summarisation of document collection's mixture of subject areas, as in the case of this study, the required competencies commonly described in job advertisements.

The two different analyses complement each other. The frequency analysis of competency-specific keywords provides insight into the general distribution of competency categories (such as, for example, analytical or communication expertise). In this way, the analysis can be used to assess the relevance of the competency categories across the examined countries and, thereby, allows the confirmation of the underlying competency framework (Brill et al., 2006). Building on this, the LSA goes beyond the distribution analysis of fixed, pre-defined competency categories and provides more exploratory insights into the common competencies stated most frequently in the job advertisements. By this means, this follow up analysis can be used to extend the underlying framework with specific core competencies from the field of lean management. The application of the two content analyses used as well as the database of lean management-related job advertisements will be presented in more detail in the following sections.

\subsection{Data collection and preparation}

A large collection of job advertisements was required to perform the computer-aided content analyses. As population of the data collection, three mature job markets were chosen, relying on the GDP (World Bank, 2018). After sorting out China as an emerging market and Japan as the historical source of lean management, the remaining three largest economies were included: The United States of America (USA), Germany (GER), and the United Kingdom (UK). The global online recruitment platform indeed.com was chosen to collect relevant advertisements from all three countries on 2016-09-29. As a meta search engine, indeed.com referenced to job postings of numerous single search engines as well as company websites. The three countries were selected in order to create a broader and diversified database from three of the world's largest economies. The database query was based on a keyword search in the job titles, using the terms "lean" OR "continuous improvement". 
Those terms were deemed to be most significant for job titles in the field of lean management (see also Section 2.2). Within the most frequent titles, the words improvement and continuous improvement are connected to roles like manager, engineer, specialist, or leader. To ensure the fit of the found 150 different postings with the scope of this study, all job advertisements were manually screened by a trained lean expert. After manually removing obviously irrelevant job advertisements as well as duplicates, a total of 2,071 advertisements (see Table 2) formed the dataset for the exploration of lean management competencies.

All job advertisements were downloaded from the platform and transferred into a unified plain text format. In addition, irrelevant sections (e.g. company profiles or contact details) were manually excluded, since such irrelevant textual data could falsify the statistical analyses. Only descriptions of the job, the responsibilities, and the requirements were used for the following analyses.

\begin{tabular}{|l|l|l|l|}
\hline $\begin{array}{l}\text { Job } \\
\text { Advertisements }\end{array}$ & GER & UK & USA \\
\hline $\mathrm{N}$ & 346 & 373 & 1,352 \\
\hline Total & \multicolumn{1}{|c|}{2,071} \\
\hline Notes & $\begin{array}{l}\text { Database: indeed.com (GER, UK, USA); search terms: „lean“ OR „continuous } \\
\text { improvement“; search field: job titles }\end{array}$ \\
\hline
\end{tabular}

Table 2. Collection of job advertisements

The collections of job advertisements had to be pre-processed for the following computer-aided analyses. In a first step, the various document contents were broken down into individual words (or terms) and summarised in term lists with their frequencies. The three term lists (GER, UK, and USA) were then further processed using lemmatisation. In this process, varying (grammatical) forms of a word are normalised to a single base or dictionary form (e.g. "goes", "going", "gone" to the base form "go"). In a next step, trivial stop words (e.g. "and", "in", "or") were automatically removed from the list using a proven stop word collection. In addition, a frequency filtering was applied, in which terms that did not appear in at least $10 \%$ of the documents were excluded. The frequency threshold of $10 \%$ was determined by iterative testing (as recommended by Evangelopoulos et al., 2012). The term list contained mostly central and meaningful terms at the $10 \%$ threshold, while lowering the threshold added mostly very specific and irrelevant terms. Afterwards, the resulting term lists were manually filtered by two independent researchers for terms irrelevant to the topic under investigation. Finally, these processes resulted in practicable term lists with 301 (GER), 323 (UK), and 421 (USA) terms. As a prerequisite for LSA, the term lists were also converted into a structured term-document matrix, where the rows contain the terms, the columns the documents, and the cells the respective frequencies. In addition, a term 
frequency - inverse document frequency (TF-IDF) weighting of the terms was performed in order to assign the terms with more representative weightings. For more detailed descriptions of the termdocument matrix and the TF-IDF weighting see Evangelopoulos et al. (2012) or Aizawa (2003).

\subsection{Categorisation of competency-specific keywords}

In this study, the relevance of competency categories was measured based on the volume of significant competency-specific keywords. The core of a sound content analysis is a clearly defined analytical construct that organises relevant categories for the topic being investigated (Krippendorff, 2013, p. 36). Such categories will provide the study with the thematic depth that it requires. Therefore, it was necessary to first define an analytical construct with valid competency categories for lean professionals. The eight competency categories discussed in Section 2.2 were chosen to form this analytical framework, since lean professionals largely work in project environments: leadership expertise, context knowledge, analytical expertise, people expertise, communication expertise, personal characteristics, project administration expertise and tools expertise.

In a next step, it was necessary to identify appropriate competency-specific keywords in the prepared term lists and to thematically allocate them to the correct competency categories. For this purpose, additional lists with the most frequent word combinations (which occurred at least in $5 \%$ of the examined job advertisements) were created per document collection (GER $=44$ word combinations; $\mathrm{UK}=67$; USA = 142). Such word combinations (e.g. root_cause_analysis) were considered to be more precise and interpretable than a list of single keywords. The frequency threshold of $5 \%$ was defined in order to exclude those word combinations from the analysis that do not occur frequently or regularly enough in the job advertisements and are therefore potentially not of interest for the identification of central competencies. There are different procedures available for threshold definition. For example, Ord et al. (2005) excluded terms from the analysis that did not have at least a frequency of 100. In this study, iterative evaluations of the generated term lists were performed in order to define the suitable frequency threshold (as recommended by Evangelopoulos et al., 2012). The frequency threshold of 5\% contained mostly central and meaningful terms, while lowering the threshold added mostly irrelevant terms. Lowering the threshold added mostly very specific and irrelevant terms. After creating a common understanding of the underlying competency categories and defining certain coding rules, two analysts then independently performed the coding process and allocated relevant keyword combinations (such as value_stream_mapping or communication_skills) into the appropriate competency categories (tools expertise and communication expertise). In order to ensure the reliability of this coding process, the agreement of the respective categorisations was evaluated. Finally, after two test rounds with a rework of the underlying coding rules, a reliable level of 0.86 was achieved (Landis and Koch, 1977, p. 165). 
Differences were discussed and the results correspondingly revised. Finally, the resulting volume of keywords per category enabled insights into the competency areas discussed most frequently in the collections of job advertisements.

\subsection{Latent semantic analysis of competencies}

LSA is an automated content analysis technique that allows comprehensive summaries of large collections of textual documents (for an introduction, see e.g. Deerwester et al., 1990; Dumais, 2004; or Landauer et al., 1998). LSA is founded on the idea that any collection of documents consists of certain contexts (e.g. individual documents, paragraphs, or sentences), as well as of words associated with these contexts. A statistical analysis of these structures, meaning the existence or non-existence of specific words or word combinations in the individual contexts, therefore allows the creation of statistical patterns of strongly-correlated words (i.e., words that often appear together in contexts) as well as strongly-correlated contexts (i.e., contexts that contain comparable combinations of words). These correlations represent specific word usage patterns, which can be interpreted as latent semantic relationships, i.e. topics, inherent in the examined collection of documents.

LSA offers two central methodological advantages for this study. First, it allows a mostly automated extraction of specific core competencies from large collections of job advertisements. Second, another advantage is the exploratory potential of LSA, which means that no pre-defined analytic framework is required. Thus, it is also able to identify previously unknown competencies. For these reasons, LSA has already been used for the evaluation of job advertisements in information systems research. Debortoli et al. (2014), for instance, applied LSA for the summarisation of more than 2,000 job advertisements in order to compare business intelligence and big data skills. Müller et al. (2016), as another example, used LSA to examine a collection of 1,507 job advertisements in order to develop a typology of business process management competencies.

\begin{tabular}{|l|l|l|}
\hline (I) Data collection and pre-processing & (II) Singular value decomposition & (III) Analysis and interpretation \\
\hline $\begin{array}{l}\text { Data collection and cleaning; } \\
\text { lemmatization; term filtering; } \\
\text { term-document matrix; term weighting }\end{array}$ & $\begin{array}{l}\text { Determination of number of factors; } \\
\text { singular value decomposition; } \\
\text { varimax rotation }\end{array}$ & $\begin{array}{l}\text { Threshold selection; interpretation of } \\
\text { factors; labeling of concepts }\end{array}$ \\
\hline
\end{tabular}

Figure 2. Phases and Tasks of Latent Semantic Analysis

The application of LSA is based on a three-step analytical process (see Figure 2): (I) data collection and pre-processing, (II) singular value decomposition and (III) factor analysis and interpretation (see also, e.g. Evangelopoulos et al., 2012, or Debortoli et al., 2014). 
I. Data collection and pre-processing. In the first phase, an appropriate collection of job advertisements had to be assembled and pre-processed. This process is described in Section 3.3. The weighted term-document matrices formed the basis for the following calculations.

II. Singular value decomposition. LSA is mathematically based on the principles of factor analysis. Specifically, a singular value decomposition (SVD) is used in order to resolve the dimensionality of large textual databases with the help of factors (see Martin and Berry, 2007, for a more detailed introduction to the mathematics of LSA). Such factors stand for a latent semantic relationship (i.e., a group of correlated words) which can be interpreted as certain topics described in the documents. In a first step, an appropriate number of factors had to be determined. Following the suggestion of Evangelopoulos et al. (2012), an iterative sensitivity analysis with qualitative assessments was performed. As a result, a total of 25 factors per document collection was determined. A larger number of factors could not reveal additional meaningful topics, and a smaller number of factors would cause the loss of relevant topics. In accordance with the suggestion by Debortoli et al. (2016), this number of topics is also practicable for the following manual interpretations. In addition, scree tests statistically confirmed the number of factors, since these factors have a high eigenvalue and explain a significant part of the variance in the data set. Then, the dimensionality reduction was performed using SVD. This means that term loadings were calculated for each of the 25 factors, so that correlating terms (words) can be clearly identified per factor. Finally, following the suggestion of Evangelopoulos et al. (2012, p. 73), a varimax rotation was applied. This statistical procedure emphasises term loadings per factor by associating each term document with a smaller number of factors, thereby supports a clearer interpretation of factors as specific topics.

III. Analysis and interpretation. First, a loading threshold had to be set, i.e. a statistical threshold from which certain high-loading terms may be assigned to a factor. Here, Evangelopoulos et al. (2012) recommended testing a varying threshold. Therefore, iterative evaluations of the generated term lists and early analysis results were used for evaluating the suitability of this loading threshold (as recommended by Evangelopoulos et al., 2012). Finally, after several test runs, thresholds between 0.26 and 0.30 were defined as to deliver meaningful results. In the next step, the assigned terms per factor could be interpreted and labelled as specific topics, i.e. competencies commonly described in the job advertisements. One short example: the correlated words "communication", "skill", "verbal", "oral", "effective", and "English" could be interpreted and labelled as the competency "communication skills". Interpretations were completed in parallel by three independent lean management experts. In case of discrepancies, they were discussed and corrected by mutual consensus. By performing separate analyses and 
translating correlated German words into English, differing language characteristics were considered. Finally, within the framework of the 25 -factor solutions, a total of 71 competencies were identified $(\mathrm{GER}=24 ; \mathrm{UK}=25 ; \mathrm{USA}=22)$, since three factors in the USA and one in GER could not be interpreted clearly. These competencies were then summarised into a structured conceptualisation (see Figure 4), inspired by the work of Debortoli et al. (2014). The competency categories discussed in Section 2.2 provided the founding framework for this. This categorisation was done by two lean management experts. An illustrative example: the identified competency of "performance measurement" was subordinated to the competency category "analytical expertise" since it stands for a specific issue in the context of this main category. A general rule in this process was that a specific competency had to appear at least in two analysis scenarios (GER, UK, or USA). This rule should ensure the relevance of the modelled competencies across the three examined document collections.

\section{$4 \quad$ Results}

\subsection{Relative importance of competency categories}

The competency categories of the analysed keywords are summarised in Figure 3 while also showing their distribution in the three countries. By this means, it is possible to assess the relevance of the competency categories and therewith to confirm the underlying competency framework (Brill et al., 2006). Analytical expertise is the most often allocated category with respectively 34 entries $(23.94 \%)$ in the USA, $26(38.81 \%)$ in the UK and $16(36.36 \%)$ in GER. This is not surprising, though, because in this category the core capabilities of lean professionals are summarised, i.e. prioritising, capturing and using knowledge and applying project management methodologies. All descriptions that deal with lean methodologies were put into this category, too, since they form the analytical backbone of the lean professional's work. The second most often cited category in all three countries is context knowledge, which was classified as all characteristics that relate to further knowledge, helping to fulfil the project goals, like the knowledge of organisational requirements, the surrounding fields related to the project as well as needed qualifications, previous experience and required degrees. Despite the smallest absolute number of entries, Germany's score in this category is with $20.45 \%$ the highest amongst them (USA: 19.72\%, UK: $16.42 \%)$. Interestingly enough, when taking a closer look into this category, in the USA and UK work experience and knowledge about the related fields seem to be more important than a specific degree, since they make up the majority of mentions (17/28 mentions and 8/11 vs. education $7 / 28$ and 1/11), whereas in the German context knowledge seems to be mainly associated with a certain type of education and degree requirements (3/9 vs. 5/9). 


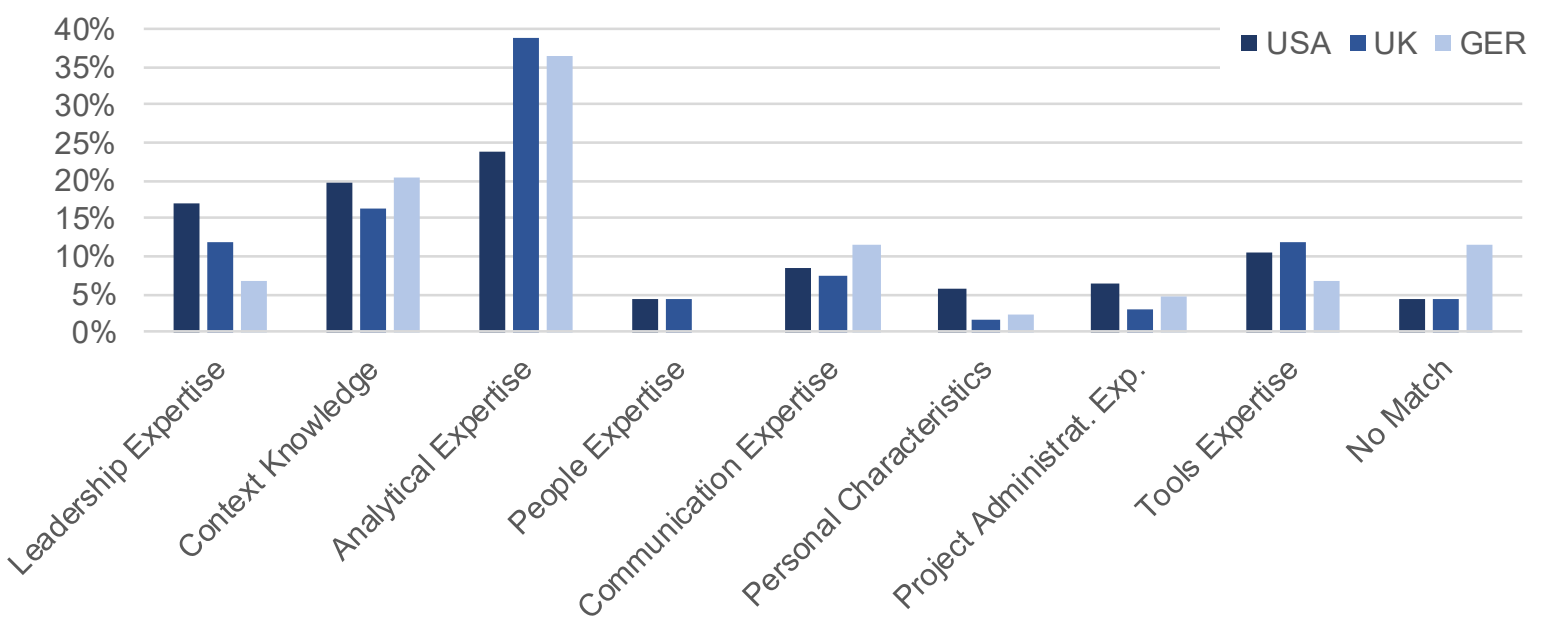

Figure 3. Per Country Keyword Distribution Regarding the Competency Categories

In the USA and UK leadership expertise is the third most often named category with $16.90 \%$ and $11.94 \%$ respectively. This might imply that the job profile of a lean professional in these two countries carries more leadership competencies comprised of responsibility and leading as well as delegation tasks than in GER with 6.82\%, where this competency seems to be of minor relevance (Robert et al., 2000). In the German job profiles, it is the communication competency that scores third highest instead $(11.36 \%)$. When looking at the communication skills in more detail, it is striking that even though they seem to have the same weight in all three countries, in GER this kind of knowledge is mostly composed of language skills (German and English) whereas in the USA and in the UK, it is more about oral and written communication skills in general and about how to communicate to a specific target group (e.g. presentation skills).

In the USA, communication expertise only ranges on the fifth position with $8.45 \%$ behind tools expertise with $10.56 \%$. In the UK, there is a similar picture: Tools expertise reaches the same score as leadership expertise (11.94\%), followed by communication expertise with $7.46 \%$. This is not surprising, given the high rate in leadership in both countries, where the job profile descriptions seem to be more about leading and delegating than about communicating.

The next most often cited competency is that of project administration expertise that scores $6.34 \%$ in the USA, $4.55 \%$ in GER, but only $2.99 \%$ in the UK.

When searching the term "six sigma" and/or the concept of "belt" as a certification for trained six sigma employees, it is interesting that those seem to have limited relevance in lean job descriptions in general. As introduced before, six sigma is not part of the general lean methodology, but it can be used as an 
extension or substitute, depending on current project goals. In GER, however, with the fewest number of word counts in total (44), six sigma appears twice and belt only once. In the UK and the USA six sigma is only named once and the concept of belt does not appear at all.

The difference in total numbers in entries of the three countries is due to the fact that only the cases up to a five percent limit were incorporated to guarantee a sufficiently relevant selection.

The problem-solving competency was deleted because of two reasons. On the one hand, there were only few mentions among the three countries, i.e. UK and USA four times, in GER no mention. On the other hand, this skill is one of the core competencies of lean professionals (Womack et al., 1991) and has been summarised under the umbrella of "analytical expertise".

\subsection{Deduction of core competencies}

Filtering the most important terms and connections out of the job postings has been the overall goal of the text mining approach. The analysis and interpretation of the method's third step combines the applied competency categories of Brill et al. (2006) with the factors from LSA to derive 71 core competencies within the three countries $(\mathrm{GER}=24 ; \mathrm{UK}=25 ; \mathrm{USA}=22)$. Table 3 contains three examples of these competencies, which were also incorporated in the final competency taxonomy (see Figure 4). The lean experts had to find a generic term (concept) to summarise as many factors as possible by considering the decreasing (text mining) importance from first to last factor. The figure shows many similarities for the competency of waste reduction between USA and UK, which is a core element of lean thinking (Thürer et al., 2017; Womack and Jones, 2003). Regarding the characteristics of demanded degrees, similarities and differences can be stated between the three countries. Job postings in all of them focus on engineering sciences. Additionally, in GER the related economic fields e.g. of engineering and management (e.g. "Wirtschaftsingenieurwesen") have been named even more often. Some of the competencies could be named very detailed, e.g. method / time study in the UK or root cause analysis in the UK and USA. Others like software skills remained very general, even if products like Microsoft Office have been named often and special software like Minitab way more infrequently. The total list of the 71 core competencies can be found in Table 4 in the appendix. 


\begin{tabular}{|l|l|l|}
\hline Concept & Country & Factors \\
\hline $\begin{array}{l}\text { Degree in } \\
\text { Engineer- } \\
\text { ing }\end{array}$ & UK & $\begin{array}{l}\text { DEGREE; ENGINEERING; EQUIVALENT; EDUCATION; MECHANICAL; } \\
\text { LEVEL; QUALIFICATION }\end{array}$ \\
\cline { 2 - 3 } & USA & $\begin{array}{l}\text { DEGREE; BACHELOR; ENGINEERING; INDUSTRIAL; EQUIVALENT; } \\
\text { SCIENCE; DISCIPLINE; UNIVERSITY; MECHANICAL; MBA; TECHNICAL; } \\
\text { EXPERIENCE; REQUIREMENT; EDUCATION }\end{array}$ \\
\hline $\begin{array}{l}\text { Degree in } \\
\text { Engineer- } \\
\text { ing (and } \\
\text { Man- } \\
\text { agement) }\end{array}$ & GER & $\begin{array}{l}\text { WIRTSCHAFTSINGENIEURWESEN; MASCHINENBAU; STUDIENGANG; } \\
\text { PRODUKTIONSTECHNIK; BETRIEBSWIRTSCHAFTSLEHRE; } \\
\text { FACHRICHTUNG; WIRTSCHAFTSWISSENSCHAFTEN; [...]; } \\
\text { WIRTSCHAFTSINFORMATIKERN ABGESCHLOSSENES; STUDIUM; } \\
\text { TECHNISCH; [...]; AUSBILDUNGEN; INGENIEUR; [...] }\end{array}$ \\
\hline $\begin{array}{l}\text { Waste } \\
\text { Reduc- } \\
\text { tion }\end{array}$ & UK & $\begin{array}{l}\text { WASTE; REDUCTION; ELIMINATE; COST; SATISFACTION; CUSTOMER; } \\
\text { INCREASE; FINANCIAL; VALUE }\end{array}$ \\
\cline { 2 - 3 } & USA & $\begin{array}{l}\text { REDUCTION; WASTE; COST; ELIMINATE; PRODUCTIVITY; DELIVERY; } \\
\text { SAFETY; QUALITY; INCREASE; TIME; SATISFACTION; IMPROVEMENT; } \\
\text { DELIVER }\end{array}$ \\
\hline
\end{tabular}

Table 3. Examples of Built Competencies from LSA Results

The last step in this analysis was the concentration of the 71 core competencies to the most important categories. Lean management experts selected those concepts with occurrences in at least two of the three analysed countries and categorised them by the presented competency framework. As an example, the degrees mentioned before resulted in the shared competency of degree in engineering. The complete result is a competency taxonomy, summarised in Figure 4, displayed as a tree diagram consisting of the overarching competency categories, the more detailed competencies associated to these categories and in two cases also very specific competencies related to them. In this competency taxonomy, the categories of people expertise and personal characteristics were not connected to specific competencies. The total of sixteen competencies are associated unequally, especially to the categories of leadership expertise, context knowledge and analytical expertise. Two specific tools have been mentioned in so many job postings, that they were included in the taxonomy, too. The communication skills represent effective communication within improvement initiatives as well as active stakeholder management (Parker et al., 2017). 


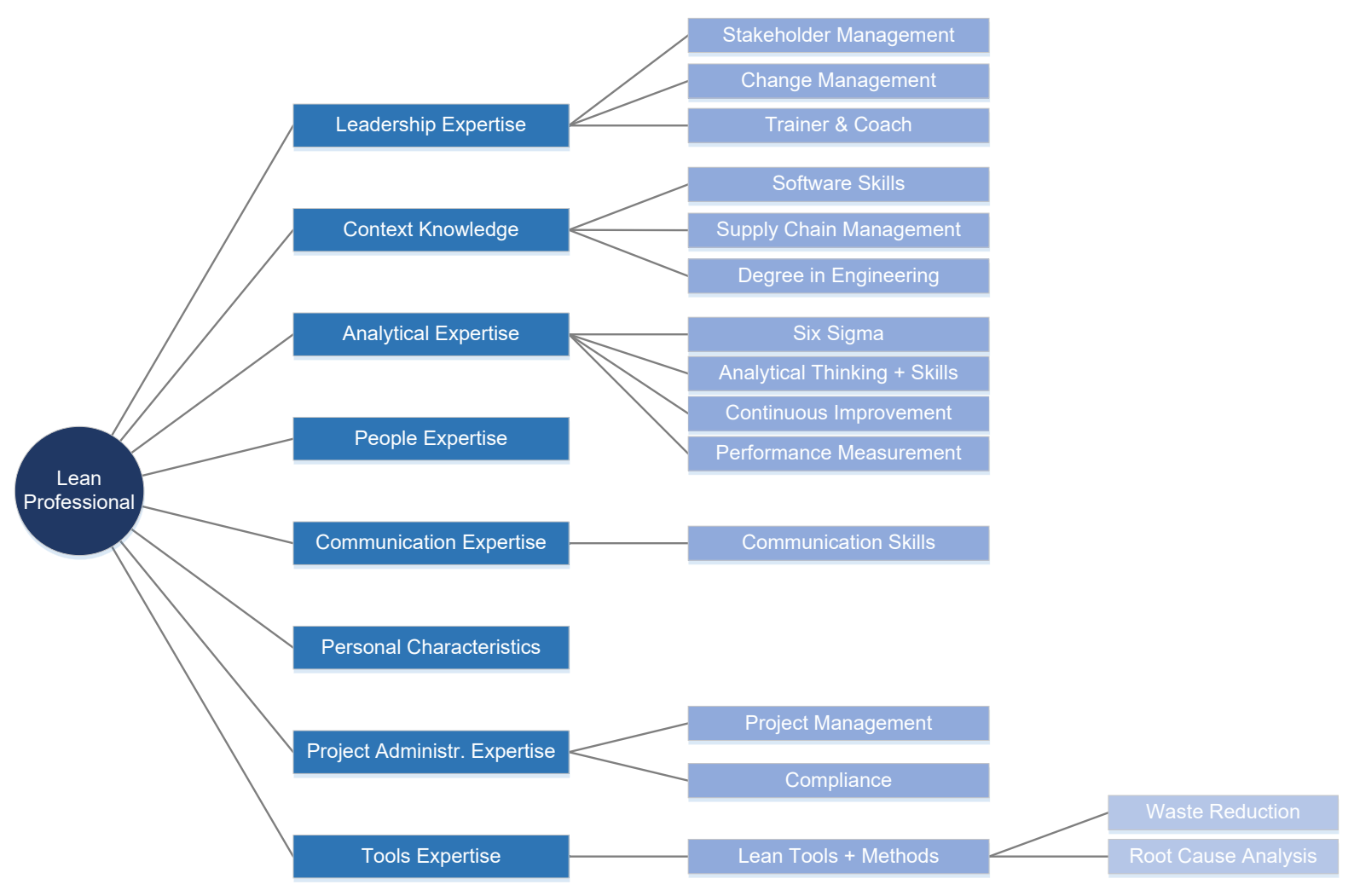

Figure 4. Lean Professional's Competency Taxonomy

\section{$5 \quad$ Discussion}

Looking at the competency distribution amongst the three countries, there are some striking facts that might hint to the specific understanding and design of a lean professional job description in the respective region. First, it is interesting that in the USA analytical and context competencies seem to almost be of the same significance, whereas in the UK and in GER context knowledge ranges only half as important as analytical knowledge. This might imply that further knowledge about the surrounding industry environment is a crucial characteristic of a lean professional in the USA. In the other two countries, this background knowledge rather seems to be a "nice-to-have" to the general skillset of a lean professional, where analytical competencies form the predominant and single most important trait.

A further striking point is that in the USA the personal characteristics seem to be of more importance than in the other countries. In the USA, the concept of "ability" is named much more often with the ability to work independently and effectively. This is not surprising when looking at the cultural dimensions developed by Hofstede and Hofstede (2005). The American (organisational) culture is characterised by a high degree of Individualism (score: 91) and Masculinity (score: 62). This implies that Americans always strive to be the best and like to talk about their success. "Many American 
assessment systems are based on precise target setting, by which American employees can show how well they did a job" (Hofstede, 2018). This is a possible explanation for the accentuation of the personal characteristics in American job advertisements. It also matches the findings by Meyer (2014), who ranked the world's countries on an eight item scale according to the interactions in business contexts: communicating, evaluating, persuading, leading, deciding, trusting, disagreeing, and scheduling. These findings are grounded in the studies of Hofstede, Hamden-Turner and Trompenaars and complemented with her own research and experience. She found out that trust in the USA is primarily built through performance (task-based) and not by means of relationships (relationship-based), i.e. business and personal relationships are not related to each other. Surprising, though, the UK scores similar on Hofstede's individualism and masculinity scale, which seem to be contradicting these results, since personal characteristics are not named that often in the UK. This, however, is in line with Meyer's (2014) findings, where the UK, still ranging on the task-side, is the country that is rather converging to the relationship-side.

Another interesting fact is that project administration expertise has a higher significance in the USA than in the other two countries. The implementation and management of projects seems to play a greater role in the American job descriptions than in the German and English ones. This again can be ascribed to the fact that American businesses are used to being measured on a regular basis, which might be a cause to make them strive yet more for good and quick results. This finding goes at least partly hand in hand with Meyer's (2014) finding that the USA is the country that is most practical-oriented (applications-first) with regard to persuading. Real world findings play the most important role, compared to ascribing more importance to theories or concepts (principles first). As a similar AngloSaxon culture, the UK ranges on the same side, whereas Germany is much more principle focused.

Language skills are placed fourth in the competency list of GER, but not mentioned in the list of the UK and USA. The ability to communicate internationally can be expected to be easier for English-speaking countries than the others, so it has not been mentioned in the job advertisements. Also, in GER the willingness to travel has been named, sometimes extended by the term internationally. In combination with the mention of the competency inhouse consulting (or consulting in general) it can be supposed, that many of the posted profiles have been about (lean) consulting jobs.

The described results for the terms of "six sigma" and "belt" could be a sign, that the approach of lean six sigma (Näslund, 2008; Drohomeretski et al., 2013) by combining lean management and six sigma is more popular in GER than in the UK and USA according to the number of terms. 


\section{Conclusion and Outlook}

This study characterises the job requirements of lean management professionals in the USA, UK, and Germany. For this purpose, it provides a comprehensive conceptualisation of competencies relevant in the field of lean management as well as statements about the relevance of eight different competency categories in this regard. In this way, the study deepens the understanding of the competencies of lean management professionals demanded by organisations.

The findings of this study provide several implications for practice. First, they can be used for assessing and developing lean management competencies on a corporate level. Especially, specific fields of the employee qualification could be revised and adjusted. Second, the findings can be used in educational institutions (e.g. universities). By comparing the existing curricula with the required skills in practice, specific adjustments of the teaching contents can be determined (Igbaria et al., 1991). Furthermore, future work should also look more in detail into the differences between the different job profiles in that area like total quality managers, business process management professionals or lean sig sigma experts, just to name a few. Like this, it can be researched what all of them have in common and what is unique to one job profile to be able to provide more purposeful job advertisements that clearly point out the expected expertise. Furthermore, it can help to delimit the different profiles from each other and by doing this, providing more specific trainings that better meet both the demand and the expectations of employers and employees equally.

The implications for research especially focus on the verification and further development of the proposed competency conceptualisation. First, the conceptualisation of required competencies could be verified from an empirical perspective. An international Delphi study with lean management experts may be an adequate means to further deepen the knowledge about lean management competencies. It could also include a large number of nations into the research and identify differences between these countries. Second, and building on that, further expansion of the conceptualisation could be carried out by specifying the concrete competency types. Also, the combination with the research of six sigma skill requirements could be promising, resulting in a competency model for lean six sigma (Arnheiter and Maleyeff, 2005; Antony, 2011) or differentiating between lean and six sigma skills. Third, a deeper analysis of an even larger set of lean professional's job profiles data could also lead to a differentiation between job roles like lean manager, continuous improvement manager or lean six sigma (master) black belt.

This study of course is not without its limitations. First, potential limitations with respect to the database used must be addressed. The job advertisements collected for this study only represent a certain 
temporary sample of all advertisements actually published in the field of lean management. It represents a snapshot of a specific point in time from a single data source. Other collections of job advertisements could potentially deliver different findings. Also, a longitudinal study over a long-term period could possibly deliver different results. Nevertheless, the study does use a comparatively large number of advertisements from three different countries. Then, although differences could be identified, the degree of distinction is naturally smaller between the USA and UK than between USA and Germany or UK and Germany. This can be ascribed to the fact that they belong to the same Anglo-Saxon, i.e. Englishspeaking country cluster, sharing the same economic ideas and principles (Hofstede, 2018). In general, all three countries are cultures of western stamp, which let them appear more alike than compared to eastern cultures. In this context, potential cultural differences in term usage (English and German) should be mentioned. In order to avoid potential translation errors, German lean terminology was evaluated and translated by experts in the field.

Furthermore, methodological limitations should be mentioned. Those arise regarding the subjective influences within the analytical approaches used. For example, the LSA required complex interpretations of the extracted factors as professional competencies. Likewise, the categorisation of keywords required a largely subjective review of the identified word combinations. Such interpretations marked by subjectivity may have introduced a certain bias to the analyses. However, in order to address this problem, such decisions have been made by several independent researchers, supplemented by a review of intercoder reliability. Second, certain analytical parameters were set by analysts, such as thresholds and the number of factors to be examined in the LSA. However, attempts were made to select parameters that would lead to the most representative and meaningful results possible. Third, the interpretive depth of the corresponding findings is limited, and does not answer the question of "why?" For example: Why exactly is stakeholder management relevant for lean professionals, and what does it look like? However, this study tries to answer these questions based on a literature-based discussion. Nevertheless, future studies could build on it by offering more concrete explanations of the required competencies (e.g. by means of expert interviews).

In conclusion, this study is a first step to identify the competencies needed by lean professionals in the form of a quantitative content analysis in three different countries that provides implications for research and for practice that need to be extended in future studies to distinguish and sharpen the role of lean management professionals. With this knowledge and the set of identified competencies, the scope of this research can be broadened, and future research can focus on the development of an independent lean professional competency framework. This however, was out of scope for this study. 


\section{Appendix}

\begin{tabular}{|c|c|c|c|}
\hline No. & Germany & United Kingdom & United States of America \\
\hline 01 & Project Management & Compliance & Change Management \\
\hline 02 & $\begin{array}{l}\text { Degree in Engineering } \\
\text { (Management) }\end{array}$ & Lean Tools & Microsoft Office Skills \\
\hline 03 & Six Sigma Belt & Budget Ownership & Degree in Engineering \\
\hline 04 & Language Skills & Microsoft Office Skills & Lean Tools \\
\hline 05 & $\begin{array}{l}\text { Interpersonal and Personal } \\
\text { Characteristics }\end{array}$ & Degree in Engineering & Root Cause Analysis \\
\hline 06 & Microsoft Office Skills & Root Cause Analysis & Waste Elimination \\
\hline 07 & Lean Methods and Tools & Waste Elimination & Communication Skills \\
\hline 08 & Supply Chain Management & Added Value & Analytical Thinking \\
\hline 09 & Personal Characteristics & Continuous Improvement & $\begin{array}{l}\text { Six Sigma and Lean } \\
\text { Certification }\end{array}$ \\
\hline 10 & Trainer and Coach & $\begin{array}{l}\text { Six Sigma and Lean } \\
\text { Methodology }\end{array}$ & Performance Measurement \\
\hline 11 & Continuous Improvement & Communication Skills & Stakeholder Management \\
\hline 12 & Professional Experience & $\begin{array}{l}\text { Production Industry } \\
\text { Experience }\end{array}$ & Supply Chain Management \\
\hline 13 & ERP Skills & Supply Chain Management & Project Management \\
\hline 14 & Controlling & Problem Solving Capability & $\begin{array}{l}\text { Production and Layout } \\
\text { Planning }\end{array}$ \\
\hline 15 & Internal Consulting & Efficient Production Layout & Benefits \\
\hline 16 & Degree & Value Stream Mapping & School Education \\
\hline 17 & Personal Characteristics & Stakeholder Management & Strategic Management \\
\hline 18 & $\begin{array}{l}\text { Willingness to Travel } \\
\text { (Internationally) }\end{array}$ & Motivational Attitude & Continuous Improvement \\
\hline 19 & $\begin{array}{l}\text { Identification of } \\
\text { Improvement Potential }\end{array}$ & Leadership & Trainer and Coach \\
\hline 20 & Best Practice Creation & Scoping and Prioritising & Compliance \\
\hline 21 & Analytical Skills & Performance Measurement & $\begin{array}{l}\text { (Analytical) Methods and } \\
\text { Tools }\end{array}$ \\
\hline 22 & Continuous Improvement & Hierarchical Position & Stakeholder Management \\
\hline 23 & Leadership & $\begin{array}{l}\text { Financial Service Industry } \\
\text { Experience }\end{array}$ & \\
\hline 24 & Operational Excellence & Facilitation Skills & \\
\hline 25 & & Method / Time Study & \\
\hline
\end{tabular}

Table 4. Core Competencies Derived from LSA and Labelled by Lean Management Experts 


\begin{tabular}{|c|c|c|c|c|c|}
\hline \multicolumn{2}{|l|}{ GERMANY } & \multicolumn{2}{|c|}{ UNITED KINGDOM } & \multicolumn{2}{|l|}{ USA } \\
\hline TERMS & \% CASES & TERMS & \% CASES & TERMS & \% CASES \\
\hline$L E A N$ & $98.27 \%$ & IMPROVE & $86.33 \%$ & EXPERIENCE & $91.57 \%$ \\
\hline MANAGEMENTS & $77.17 \%$ & LEAN & $85.79 \%$ & IMPROVE & $89.57 \%$ \\
\hline ANFORDERUNGEN & $72.83 \%$ & EXPERIENCE & $84.45 \%$ & $L E A N$ & $87.20 \%$ \\
\hline JOBTITEL & $71.68 \%$ & MANAGEMENT & $81.77 \%$ & MANAGEMENT & $84.39 \%$ \\
\hline JOBBESCHREIBUNG & $71.10 \%$ & CONTINUOUS & $76.14 \%$ & WORK & $83.80 \%$ \\
\hline ERFAHRUNGEN & $57.23 \%$ & PROJECT & $68.36 \%$ & REQUIREMENT & $82.84 \%$ \\
\hline STUDIUMS & $52.89 \%$ & WORK & $67.56 \%$ & PROCESS & $80.25 \%$ \\
\hline KENNTNISSE & $51.73 \%$ & SKILL & $64.34 \%$ & CONTINUOUS & $78.92 \%$ \\
\hline OFFICE & $46.53 \%$ & TEAM & $61.13 \%$ & SKILL & $76.63 \%$ \\
\hline ENGLISCHKENNTNISSE & $45.95 \%$ & BUSINESS & $60.59 \%$ & DEGREE & $75.89 \%$ \\
\hline METHODEN & $44.80 \%$ & PROCESS & $57.91 \%$ & TEAM & $75.00 \%$ \\
\hline DURCHFÜHRUNG & $43.93 \%$ & DEVELOPMENT & $53.35 \%$ & PROJECT & $74.33 \%$ \\
\hline ABGESCHLOSSENES & $43.64 \%$ & SIGMA & $51.74 \%$ & DEVELOPMENT & $73.52 \%$ \\
\hline UNTERSTÜTZUNG & $38.15 \%$ & LEAD & $50.94 \%$ & RESPONSIBILITY & $72.12 \%$ \\
\hline WORKSHOPS & $37.86 \%$ & MANUFACTURE & $49.33 \%$ & $L E A D$ & $67.53 \%$ \\
\hline UMSETZUNGEN & $36.71 \%$ & SUPPORT & $49.06 \%$ & COMMUNICATION & $66.49 \%$ \\
\hline PROJEKTEN & $34.97 \%$ & ENVIRONMENT & $49.06 \%$ & ABILITY & $64.42 \%$ \\
\hline BERUFSERFAHRUNGEN & $32.37 \%$ & CHANGE & $47.45 \%$ & $L E A D E R$ & $62.43 \%$ \\
\hline TEAMS & $30.92 \%$ & $L E V E L$ & $46.11 \%$ & SUPPORT & $62.43 \%$ \\
\hline OPTIMIERUNGEN & $30.92 \%$ & REQUIREMENT & $45.84 \%$ & BUSINESS & $61.69 \%$ \\
\hline UMGANGS & $29.77 \%$ & IDENTIFY & $45.58 \%$ & TRAINING & $60.80 \%$ \\
\hline ARBEITSWEISE & $28.61 \%$ & ABILITY & $45.04 \%$ & TOOL & $56.95 \%$ \\
\hline DEUTSCH & $28.61 \%$ & IMPLEMENTATION & $43.70 \%$ & SIGMA & $56.88 \%$ \\
\hline PROZESSEN & $28.32 \%$ & ROLE & $43.16 \%$ & ORGANIZATION & $56.73 \%$ \\
\hline MANAGERN & $27.46 \%$ & COMMUNICATION & $42.90 \%$ & IMPLEMENTATION & $56.58 \%$ \\
\hline WEITERENTWICKLUNG & $26.88 \%$ & JOBBESCHREIBUNG & $41.55 \%$ & BACHELOR & $56.07 \%$ \\
\hline ANALYSEN & $26.88 \%$ & ANFORDERUNGEN & $41.55 \%$ & LEVEL & $55.10 \%$ \\
\hline MITARBEITERN & $25.72 \%$ & JOBTITEL & $41.29 \%$ & MANUFACTURE & $55.03 \%$ \\
\hline PRODUKTIONEN & $24.57 \%$ & DELIVER & $40.75 \%$ & IDENTIFY & $54.44 \%$ \\
\hline SIGMA & $23.70 \%$ & RESPONSIBILITY & $40.21 \%$ & PROVIDE & $52.51 \%$ \\
\hline ENTWICKLUNGEN & $23.70 \%$ & STRONG & $39.68 \%$ & QUALITY & $52.00 \%$ \\
\hline WIRTSCHAFTSINGENIEURWESEN & $23.70 \%$ & EXCELLENCE & $39.14 \%$ & SYSTEM & $51.70 \%$ \\
\hline$S I X$ & $23.41 \%$ & KNOWLEDGE & $38.87 \%$ & ANALYSIS & $51.70 \%$ \\
\hline ERFOLGREICHEN & $23.12 \%$ & ENSURE & $38.61 \%$ & PROBLEM & $51.55 \%$ \\
\hline HOHEN & $22.54 \%$ & TOOL & $38.34 \%$ & KNOWLEDGE & $50.37 \%$ \\
\hline ANWENDUNGEN & $22.25 \%$ & INCLUDE & $37.80 \%$ & ENVIRONMENT & $50.15 \%$ \\
\hline AUFGABEN & $21.68 \%$ & USE & $36.19 \%$ & FUNCTION & $50.07 \%$ \\
\hline FÄHIGKEITEN & $20.81 \%$ & KEY & $35.66 \%$ & ENGINEERING & $50.00 \%$ \\
\hline ARBEITENS & $20.52 \%$ & LEADER & $35 \cdot 39 \%$ & RELATE & $49.04 \%$ \\
\hline MEHRJÄHRIGE & $20.52 \%$ & UNDERSTAND & $34.58 \%$ & $P L A N$ & $47.78 \%$ \\
\hline PROFILE & $20.52 \%$ & ENGINEERING & $34 \cdot 32 \%$ & QUALIFICATION & $47.12 \%$ \\
\hline MASCHINENBAU & $20.23 \%$ & TRAINING & $33.51 \%$ & EFFECTIVE & $46.82 \%$ \\
\hline SCHRIFTEN & $20.23 \%$ & QUALIFICATION & $33.51 \%$ & STRONG & $46.52 \%$ \\
\hline WORTES & $20.23 \%$ & TECHNIQUE & $33.24 \%$ & EDUCATION & $46.23 \%$ \\
\hline AUSBILDUNGEN & $19.36 \%$ & IMPROVEMENT & $33.24 \%$ & DEMONSTRATE & $45.78 \%$ \\
\hline PROJEKTE & $19,36 \%$ & INFLUENCE & $32.71 \%$ & PROGRAM & $44.45 \%$ \\
\hline PLANUNGEN & $19,08 \%$ & ANALYSIS & $32.17 \%$ & SOLVE & $44.38 \%$ \\
\hline PROJEKTMANAGEMENT & $19,08 \%$ & DELIVERY & $31.90 \%$ & EXCELLENCE & $44.16 \%$ \\
\hline REISEBEREITSCHAFT & $19,08 \%$ & PERFORMANCE & $31.64 \%$ & TIME & $43.12 \%$ \\
\hline IMPLEMENTIERUNG & $18,79 \%$ & EFFECTIVE & $31.37 \%$ & ENSURE & $42.83 \%$ \\
\hline
\end{tabular}

Table 5. 50 most frequent terms in GER, UK, USA 


\begin{tabular}{|c|c|c|}
\hline Job Titles & FREQUENCY & \% of CASES \\
\hline CONTINUOUS IMPROVEMENT MANAGER & 270 & $15.68 \%$ \\
\hline LEAN SIX SIGMA (MASTER) BLACK BELT & 247 & $14.37 \%$ \\
\hline CONTINUOUS IMPROVEMENT ENGINEER & 118 & $6.85 \%$ \\
\hline CONTINUOUS IMPROVEMENT SPECIALIST & 67 & $3.89 \%$ \\
\hline CONTINUOUS IMPROVEMENT LEADER & 57 & $3.31 \%$ \\
\hline LEAN MANAGER & 39 & $2.26 \%$ \\
\hline LEAN ENGINEER & 33 & $1.92 \%$ \\
\hline MANUFACTURING ENGINEER & 33 & $1.92 \%$ \\
\hline CONTINUOUS IMPROVEMENT LEADER & 25 & $1.45 \%$ \\
\hline PROCESS ENGINEER & 24 & $1.39 \%$ \\
\hline LEAN LEADER & 23 & $1.34 \%$ \\
\hline CONTINUOUS IMPROVEMENT ANALYST & 22 & $1.28 \%$ \\
\hline CONTINUOUS IMPROVEMENT COORDINATOR & 22 & $1.28 \%$ \\
\hline DIRECTOR OF CONTINUOUS & 22 & $1.28 \%$ \\
\hline PROJECT MANAGER & 20 & $1.16 \%$ \\
\hline DIRECTOR OF CONTINUOUS IMPROVEMENT & 18 & $1.05 \%$ \\
\hline LEAN MANUFACTURING ENGINEER & 18 & $1.05 \%$ \\
\hline INDUSTRIAL ENGINEER & 16 & $0.93 \%$ \\
\hline LEAN COORDINATOR & 15 & $0.87 \%$ \\
\hline MASTER BLACK BELT & 14 & $0.81 \%$ \\
\hline LEAN SPECIALIST & 13 & $0.75 \%$ \\
\hline MANAGEMENT CONSULTANT & 13 & $0.75 \%$ \\
\hline MANAGER LEAN MANAGEMENT & 13 & $0.75 \%$ \\
\hline PROCESS ANALYST & 13 & $0.75 \%$ \\
\hline IMPROVEMENT CONSULTANT & 12 & $0.70 \%$ \\
\hline LEAN CONSULTANT & 12 & $0.70 \%$ \\
\hline LEAN FACILITATOR & 12 & $0.70 \%$ \\
\hline LEAN SUPPLY CHAIN MANAGER & 11 & $0.64 \%$ \\
\hline LEAN COACH & 10 & $0.58 \%$ \\
\hline LEAN MANUFACTURING MANAGER & 10 & $0.58 \%$ \\
\hline CONTINUOUS IMPROVEMENT PROJECT MANAGER & 9 & $0.52 \%$ \\
\hline LEAN TECHNICIAN & 9 & $0.52 \%$ \\
\hline QUALITY AND CONTINUOUS IMPROVEMENT MANAGER & 9 & $0.52 \%$ \\
\hline LEAN PRACTITIONER & 8 & $0.46 \%$ \\
\hline PROCESS IMPROVEMENT MANAGER & 8 & $0.46 \%$ \\
\hline PROJECT ENGINEER & 8 & $0.46 \%$ \\
\hline QUALITY ENGINEER & 8 & $0.46 \%$ \\
\hline BUSINESS ANALYST & 7 & $0.41 \%$ \\
\hline BUSINESS PROCESS ANALYST & 7 & $0.41 \%$ \\
\hline CONTINUOUS IMPROVEMENT DELIVERY MANAGER & 7 & $0.41 \%$ \\
\hline LEAN PROCESS ENGINEER & 7 & $0.41 \%$ \\
\hline LEAN SIGMA & 7 & $0.41 \%$ \\
\hline LEAN SIX SIGMA MANAGER & 7 & $0.41 \%$ \\
\hline LEAN SIX SIGMA PROJECT & 7 & $0.41 \%$ \\
\hline PROGRAM MANAGER & 7 & $0.41 \%$ \\
\hline CHANGE SPECIALIST & 6 & $0.35 \%$ \\
\hline LEAN AGILE COACH & 6 & $0.35 \%$ \\
\hline LEAN CHAMPION & 6 & $0.35 \%$ \\
\hline LEAN EXPERT & 6 & $0.35 \%$ \\
\hline LEAN SUPPLY CHAIN MANAGER & 6 & $0.35 \%$ \\
\hline
\end{tabular}

Table 6. Lean management job titles 


\section{References}

Achanga, P., Shehab, E., Roy, R. and Nelder, G. (2006), "Critical success factors for lean implementation within SMEs", Journal of Manufacturing Technology Management, Vol. 17 No. 4, pp. 460-471.

Ahsan, K., Ho, M. and Khan, S. (2013), "Recruiting Project Managers. A Comparative Analysis of Competencies and Recruitment Signals From Job Advertisements", Project Management Journal, Vol. 44 No. 5, pp. 36-54.

Aizawa, A. (2003), "An information-theoretic perspective of tf-idf measures", Information Processing \& Management, Vol. 39 No. 1, pp. 45-65.

Albliwi, S., Antony, J., Abdul Halim Lim, S. and van der Wiele, T. (2014), "Critical failure factors of Lean Six Sigma. A systematic literature review", International Journal of Quality \& Reliability Management, Vol. 31 No. 9, pp. 1012-1030.

Albliwi, S.A., Antony, J. and Lim, S.A.h. (2015), "A systematic review of Lean Six Sigma for the manufacturing industry”, Business Process Management Journal, Vol. 21 No. 3, pp. 665-691.

Alldredge, M.E. and Nilan, K.J. (2000), "3M's leadership competency model. An internally developed solution”, Human Resource Management, Vol. 39 No. 2-3, pp. 133-145.

Altinkemer, K., Ozcelik, Y. and Ozdemir, Z.D. (2011), "Productivity and Performance Effects of Business Process Reengineering. A Firm-Level Analysis", Journal of Management Information Systems, Vol. 27 No. 4, pp. 129-162.

Angelis, J., Conti, R., Cooper, C. and Gill, C. (2011), "Building a high-commitment lean culture", Journal of Manufacturing Technology Management, Vol. 22 No. 5, pp. 569-586.

Antony, J. (2006), "Six sigma for service processes", Business Process Management Journal, Vol. 12 No. 2, pp. 234-248.

Antony, J. (2011), "Six Sigma vs Lean. Some perspectives from leading academics and practitioners", International Journal of Productivity and Performance Management, Vol. 60 No. 2, pp. 185-190.

Antony, J., Douglas, A. and Antony, F.J. (2007), "Determining the essential characteristics of Six Sigma Black Belts. Results from a pilot study in UK manufacturing companies", The TQM Magazine, Vol. 19 No. 3, pp. 274-281.

Antony, J. and Karaminas, H. (2016), "Critical assessment on the Six Sigma Black Belt roles/responsibilities, skills and training", International Journal of Quality \& Reliability Management, Vol. 33 No. 5, pp. 558-573.

Arnheiter, E.D. and Maleyeff, J. (2005), "The integration of lean management and Six Sigma", The TQM Magazine, Vol. 17 No. 1, pp. 5-18.

Association for Project Management (2015), APM Competence Framework, 2nd ed., Buckinghamshire, UK.

Berelson, B. (1952), Content analysis in communication research., Free Press, Glencoe, Illinois.

Bessant, J., Caffyn, S. and Gallagher, M. (2001), "An evolutionary model of continuous improvement behaviour", Technovation, Vol. 21 No. 2, pp. 67-77.

Bessant, J. and Francis, D. (1999), "Developing strategic continuous improvement capability", International Journal of Operations \& Production Management, Vol. 19 No. 11, pp. 1106-1119.

Bhasin, S. and Burcher, P. (2006), "Lean viewed as a philosophy", Journal of Manufacturing Technology Management, Vol. 17 No. 1, pp. 56-72. 
Black, K. and McGlashan, R. (2006), "Essential characteristics of Six Sigma Black Belt candidates. A study of US companies", International Journal of Six Sigma and Competitive Advantage, Vol. 2 No. 3, pp. 301-312.

Bortolotti, T., Boscari, S. and Danese, P. (2015), "Successful lean implementation. Organizational culture and soft lean practices", International Journal of Production Economics, Vol. 160, pp. $182-201$.

Brill, J.M., Bishop, M.J. and Walker, A.E. (2006), "The Competencies and Characteristics Required of an Effective Project Manager. A Web-Based Delphi Study", Educational Technology Research and Development, Vol. 54 No. 2, pp. 115-140.

Brunet, A.P. and New, S. (2003), "Kaizen in Japan. An empirical study", International Journal of Operations \& Production Management, Vol. 23 No. 12, pp. 1426-1446.

Cachay, J. and Abele, E. (2012), "Developing Competencies for Continuous Improvement Processes on the Shop Floor through Learning Factories. Conceptual Design and Empirical Validation", Procedia CIRP, Vol. 3, pp. 638-643.

De Bruin, T. and Rosemann, M. (2007), "Using the Delphi Technique to Identify BPM Capability Areas", paper presented at ACIS, 5-7 December 2007, Toowoomba, Australia, available at: http://aisel.aisnet.org/acis2007/42.

Debortoli, S., Müller, O., Junglas, I. and vom Brocke, J. (2016), “Text Mining For Information Systems Researchers: An Annotated Topic Modeling Tutorial", Communications of the Association for Information Systems, Vol. 39 No. 1.

Debortoli, S., Müller, O. and vom Brocke, J. (2014), "Comparing Business Intelligence and Big Data Skills. A Text Mining Study Using Job Advertisements”, Business \& Information Systems Engineering, Vol. 6 No. 5, pp. 289-300.

Deerwester, S., Dumais, S.T., Furnas, G.W., Landauer, T.K. and Harshman, R. (1990), "Indexing by latent semantic analysis", Journal of the American society for information science, Vol. 41 No. 6 , pp. 391-407.

Drohomeretski, E., Gouvea da Costa, Sergio E., Pinheiro de Lima, E. and Garbuio, Paula Andrea da Rosa (2013), "Lean, Six Sigma and Lean Six Sigma. An analysis based on operations strategy", International Journal of Production Research, Vol. 52 No. 3, pp. 804-824.

Dumais, S.T. (2004), "Latent semantic analysis", Annual Review of Information Science and Technology, Vol. 38 No. 1, pp. 188-230.

Dumas, M. (2013), Fundamentals of business process management, Springer, Berlin, New York.

Easton, G.S. and Rosenzweig, E.D. (2012), "The role of experience in six sigma project success. An empirical analysis of improvement projects", Journal of Operations Management, Vol. 30 No. 78, pp. 481-493.

El-Sabaa, S. (2001), “The skills and career path of an effective project manager", International Journal of Project Management, Vol. 19 No. 1, pp. 1-7.

Emiliani, M.L. (2003), "Linking leaders' beliefs to their behaviors and competencies", Management Decision, Vol. 41 No. 9, pp. 893-910.

European Committee for Standardization (2018), “A common European framework for ICT Professionals in all industry sectors. EN 16234-1:2016", available at:

http://www.ecompetences.eu/ (accessed 1 March 2018). 
Evangelopoulos, N., Zhang, X. and Prybutok, V.R. (2012), "Latent Semantic Analysis. Five methodological recommendations", European Journal of Information Systems, Vol. 21 No. 1, pp. $70-86$.

Fisher, E. (2011), "What practitioners consider to be the skills and behaviours of an effective people project manager", International Journal of Project Management, Vol. 29 No. 8, pp. 994-1002.

Fullerton, R.R. and McWatters, C.S. (2001), "The production performance benefits from JIT implementation", Journal of Operations Management, Vol. 19 No. 1, pp. 81-96.

Gorbacheva, E., Stein, A., Schmiedel, T. and Müller, O. (2016), "The Role of Gender in Business Process Management Competence Supply”, Business \& Information Systems Engineering, Vol. 58 No. 3, pp. 213-231.

Haikonen, A., Savolainen, T. and Järvinen, P. (2004), "Exploring Six Sigma and CI capability development. Preliminary case study findings on management role", Journal of Manufacturing Technology Management, Vol. 15 No. 4, pp. 369-378.

Heckl, D., Moormann, J. and Rosemann, M. (2010), "Uptake and success factors of Six Sigma in the financial services industry", Business Process Management Journal, Vol. 16 No. 3, pp. 436-472.

Hicks, B.J. (2007), "Lean information management. Understanding and eliminating waste", International Journal of Information Management, Vol. 27 No. 4, pp. 233-249.

Higgs, M. and Rowland, D. (2000), "Building change leadership capability. 'The quest for change competence", Journal of Change Management, Vol. 1 No. 2, pp. 116-130.

Hines, P., Holweg, M. and Rich, N. (2004), "Learning to evolve. A review of contemporary lean thinking", International Journal of Operations \& Production Management, Vol. 24 No. 10, pp. 994-1011.

Hofstede, G. (2018), “United States”, available at: https://www.hofstede-insights.com/countrycomparison/the-usa/ (accessed 1 March 2018).

Hofstede, G.H. and Hofstede, G.J. (2005), Cultures and organizations: Software of the mind, The successful strategist series, 2nd ed., McGraw-Hill, New York.

Igbaria, M., Greenhaus, J.H. and Parasuraman, S. (1991), "Career Orientations of MIS Employees. An Empirical Analysis”, MIS Quarterly, Vol. 15 No. 2, pp. 151-169.

Imai, M. (1986), Kaizen, the key to Japan's competitive success, Random House Business Division, New York.

Indulska, M., Hovorka, D.S. and Recker, J. (2012), "Quantitative approaches to content analysis. Identifying conceptual drift across publication outlets", European Journal of Information Systems, Vol. 21 No. 1, pp. 49-69.

International Standards Office (2011a), Quantitative methods in process improvement -- Six Sigma -Part 1: DMAIC methodology, Vol. 03.120.30 No. 13053-1:2011, available at: https://www.iso.org/standard/52901.html.

International Standards Office (2011b), Quantitative methods in process improvement -- Six Sigma -Part 2: Tools and techniques, Vol. 03.120.30 No. 13053-2:2011, available at: https://www.iso.org/standard/52902.html (accessed 1 January 2019).

Ittner, C.D. and Larcker, D.F. (1997), “The Performance Effects of Process Management Techniques”, Management Science, Vol. 43 No. 4, pp. 522-534.

Karlsson, C. and Åhlström, P. (1996), “Assessing changes towards lean production”, International Journal of Operations \& Production Management, Vol. 16 No. 2, pp. 24-41. 
Kettenbohrer, J., Beimborn, D. and Eckhardt, A. (2016), "Examining the influence of perceived job characteristics on employees' process orientation", Paper 165, paper presented at European Conference on Information Systems, 2016, Istanbul, Turkey.

Kettinger, W.J., Teng, J.T.C. and Guha, S. (1997), "Business Process Change. A Study of Methodologies, Techniques, and Tools", MIS Quarterly, Vol. 21 No. 1, pp. 55-80.

Kohlbacher, M. and Reijers, H.A. (2013), "The effects of process-oriented organizational design on firm performance", Business Process Management Journal, Vol. 19 No. 2, pp. 245-262.

Kotter, J.P. (1996), Leading Change, Harvard Business School Press, Boston, USA.

Krippendorff, K. (2013), Content analysis: An introduction to its methodology, 3rd ed., Sage, Los Angeles, London.

Landauer, T.K., Foltz, P.W. and Laham, D. (1998), "An introduction to latent semantic analysis", Discourse Processes, Vol. 25 No. 2-3, pp. 259-284.

Landis, J.R. and Koch, G.G. (1977), "The Measurement of Observer Agreement for Categorical Data", Biometrics, Vol. 33 No. 1, pp. 159-174.

Lawler, E.E. (1994), "From job-based to competency-based organizations", Journal of Organizational Behavior, Vol. 15 No. 1, pp. 3-15.

Lee, D.M.S., Trauth, E.M. and Farwell, D. (1995), "Critical Skills and Knowledge Requirements of IS Professionals. A Joint Academic/Industry Investigation”, MIS Quarterly, Vol. 19 No. 3, pp. 313340.

Lee, H.-J. (2004), "The role of competence-based trust and organizational identification in continuous improvement", Journal of Managerial Psychology, Vol. 19 No. 6, pp. 623-639.

Lewis, M.A. (2000), "Lean production and sustainable competitive advantage", International Journal of Operations \& Production Management, Vol. 20 No. 8, pp. 959-978.

Liker, J.K. and Morgan, J.M. (2006), "The Toyota Way in Services. The Case of Lean Product Development", Academy of Management Perspectives, Vol. 20 No. 2, pp. 5-20.

Lohmann, P. and Zur Muehlen, M. (2015), "Business Process Management Skills and Roles. An Investigation of the Demand and Supply Side of BPM Professionals", in Motahari-Nezhad, H.R., Recker, J. and Weidlich, M. (Eds.), Business Process Management Conference Proceedings, Lecture Notes in Computer Science, Vol. 9253, Springer, Cham, pp. 317-332.

Martin, D.I. and Berry, M.W. (2007), "Mathematical foundations behind latent semantic analysis", in Landauer, T.K., McNamara, D.S., Dennis, S. and Kintsch, W. (Eds.), Handbook of Latent Semantic Analysis, University of Colorado Institute of Cognitive Science Series, Psychology Press, Mahwah, NJ, pp. 33-57.

Meyer, E. (2014), The culture map: Decoding how people think, lead, and get things done across cultures, PublicAffairs, New York.

Müller, O., Schmiedel, T., Gorbacheva, E. and vom Brocke, J. (2016), “Towards a typology of business process management professionals. Identifying patterns of competences through latent semantic analysis", Enterprise Information Systems, Vol. 10 No. 1, pp. 50-80.

Müller, R. and Turner, R. (2010), "Leadership competency profiles of successful project managers", International Journal of Project Management, Vol. 28 No. 5, pp. 437-448.

Murawski, M. and Bick, M. (2017), "Digital competences of the workforce - a research topic?", Business Process Management Journal, Vol. 23 No. 3, pp. 721-734. 
Näslund, D. (2008), “Lean, six sigma and lean sigma. Fads or real process improvement methods?", Business Process Management Journal, Vol. 14 No. 3, pp. 269-287.

Needy, K.L., Norman, B.A., Bidanda, B., Ariyawongrat, P., Tharmmaphornphilas, W. and Warner, R.C. (2015), "Assessing Human Capital. A Lean Manufacturing Example”, Engineering Management Journal, Vol. 14 No. 3, pp. 35-39.

Negrão, L.L.L., Godinho Filho, M. and Marodin, G. (2017), "Lean practices and their effect on performance. A literature review", Production Planning \& Control, Vol. 28 No. 1, pp. 33-56.

Nelson, R.R. (1991), "Educational Needs as Perceived by IS and End-User Personnel. A Survey of Knowledge and Skill Requirements", MIS Quarterly, Vol. 15 No. 4, pp. 503-525.

Nordhaug, O. (1993), Human capital in organizations: Competence, training, and learning, Scandinavian University Press; Oxford University Press, Oslo, New York.

Ord, T.J., Martins, E.P., Thakur, S., Mane, K.K. and Börner, K. (2005), "Trends in animal behaviour research (1968-2002). Ethoinformatics and the mining of library databases", Animal Behaviour, Vol. 69 No. 6, pp. 1399-1413.

Paim, R., Mansur Caulliraux, H. and Cardoso, R. (2008), "Process management tasks. A conceptual and practical view", Business Process Management Journal, Vol. 14 No. 5, pp. 694-723.

Pant, I. and Baroudi, B. (2008), "Project management education. The human skills imperative", International Journal of Project Management, Vol. 26 No. 2, pp. 124-128.

Parker, D.W., Kunde, R. and Zeppetella, L. (2017), "Exploring communication in project-based interventions", International Journal of Productivity and Performance Management, Vol. 66 No. 2, pp. 146-179.

Parry, G., Mills, J. and Turner, C. (2010), "Lean competence. Integration of theories in operations management practice", Supply Chain Management: An International Journal, Vol. 15 No. 3, pp. $216-226$.

Pettersen, J. (2009), "Defining lean production. Some conceptual and practical issues", The TQM Journal, Vol. 21 No. 2, pp. 127-142.

Pettersen, N. (1991), "What do we know about the effective project manager?", International Journal of Project Management, Vol. 9 No. 2, pp. 99-104.

Ramadas, T. and Satish, K.P. (2018), "Identification and modeling of employee barriers while implementing lean manufacturing in small- and medium-scale enterprises", International Journal of Productivity and Performance Management, Vol. 67 No. 3, pp. 467-486.

Recht, R. and Wilderom, C.P.M. (1998), "Kaizen and culture. On the transferability of Japanese suggestion systems", International Business Review, Vol. 7 No. 1, pp. 7-22.

Robert, C., Probst, T.M., Martocchio, J.J., Drasgow, F. and Lawler, J.J. (2000), "Empowerment and continuous improvement in the United States, Mexico, Poland, and India. Predicting fit on the basis of the dimensions of power distance and individualism", Journal of Applied Psychology, Vol. 85 No. 5, pp. 643-658.

Rosemann, M. and vom Brocke, J. (2015), "The Six Core Elements of Business Process Management", in vom Brocke, J. and Rosemann, M. (Eds.), Handbook on Business Process Management 1: Introduction, Methods, and Information Systems, International handbooks on information systems, 2nd ed., Springer, Berlin Heidelberg, pp. 105-122.

Schmiedel, T., vom Brocke, J. and Recker, J. (2013), "Which cultural values matter to business process management? Results from a global Delphi study", Business Process Management Journal, Vol. 19 No. 2, pp. 292-317. 
Schmiedel, T., vom Brocke, J. and Recker, J. (2014), "Development and validation of an instrument to measure organizational cultures' support of Business Process Management", Information \& Management, Vol. 51 No. 1, pp. 43-56.

Schroeder, R.G., Linderman, K., Liedtke, C. and Choo, A.S. (2008), "Six Sigma. Definition and underlying theory", Journal of Operations Management, Vol. 26 No. 4, pp. 536-554.

Shah, R. and Ward, P.T. (2007), "Defining and developing measures of lean production", Journal of Operations Management, Vol. 25 No. 4, pp. 785-805.

Shearer, C. (2000), "The CRISP-DM Model. The New Blueprint for Data Mining", Journal of Data Warehousing, Vol. 5 No. 4, pp. 13-22.

Sidorova, A. and Isik, O. (2010), "Business process research. A cross-disciplinary review", Business Process Management Journal, Vol. 16 No. 4, pp. 566-597.

Skulmoski, G.J. and Hartman, F.T. (2010), "Information systems project manager soft competencies. A project-phase investigation”, Project Management Journal, Vol. 41 No. 1, 61-80.

Tang, H.-L., Lee, S. and Koh, S. (2001), "Educational Gaps as Perceived by is Educators. A Survey of Knowledge and Skill Requirements", Journal of Computer Information Systems, Vol. 41 No. 2, pp. $76-84$.

Thürer, M., Tomašević, I. and Stevenson, M. (2017), "On the meaning of 'Waste'. Review and definition", Production Planning \& Control, Vol. 28 No. 3, pp. 244-255.

Todd, P.A., McKeen, J.D. and Gallupe, R.B. (1995), “The Evolution of IS Job Skills. A Content Analysis of IS Job Advertisements from 1970 to 1990", MIS Quarterly, Vol. 19 No. 1, pp. 1-27.

Treville, S. and Antonakis, J. (2006), "Could lean production job design be intrinsically motivating? Contextual, configurational, and levels-of-analysis issues", Journal of Operations Management, Vol. 24 No. 2, pp. $99-123$.

Trkman, P. (2010), “The critical success factors of business process management”, International Journal of Information Management, Vol. 30 No. 2, pp. 125-134.

Trompenaars, F. and Hampden-Turner, C. (2000), Riding the Waves of Culture: Understanding Cultural Diversity in Business, Nicholas Brealey Publishing, London.

Usdol/Eta (2018), “O*NET Resource Center - Overview”, US Department of Labor/Employment and Training Administration, available at: https://www.onetcenter.org/overview.html (accessed 1 January 2019).

Vakola, M., Soderquist, K.E. and Prastacos, G.P. (2007), "Competency management in support of organisational change", International Journal of Manpower, Vol. 28 No. 3/4, pp. 260-275.

van Dun, D.H., Hicks, J.N. and Wilderom, C.P.M. (2017), "Values and behaviors of effective lean managers. Mixed-methods exploratory research", European Management Journal, Vol. 35 No. 2, pp. 174-186.

van Dun, D.H. and Wilderom, C.P.M. (2016), "Lean-team effectiveness through leader values and members' informing", International Journal of Operations \& Production Management, Vol. 36 No. 11, pp. 1530-1550.

Vieru, D. (2015), "Towards a Multi-Dimensional Model of Digital Competence in Small- and Medium-Sized Enterprises", in Khosrowpour, M. (Ed.), Encyclopedia of information science and technology, 3rd ed., Information Science Reference, Hershey, Pa., pp. 6715-6725. 
Vlachos, I. and Siachou, E. (2018), “An empirical investigation of workplace factors affecting lean performance", International Journal of Productivity and Performance Management, Vol. 67 No. 2, 278-296.

vom Brocke, J. and Sinnl, T. (2011), "Culture in business process management. A literature review", Business Process Management Journal, Vol. 17 No. 2, pp. 357-378.

Weber, R.P. (1990), Basic Content Analysis, Vol. 49, 2nd ed., SAGE Publications, Newbury Park, CA.

Womack, J.P. and Jones, D.T. (2003), Lean thinking: Banish waste and create wealth in your corporation, Free Press, New York.

Womack, J.P., Jones, D.T. and Roos, D. (1991), The machine that changed the world: How Japan's secret weapon in the global auto wars will revolutionize western industry, Harper Perennial, New York.

World Bank (2018), "Gross domestic product 2016. World Development Indicators database", available at: https://databank.worldbank.org/data/download/GDP.pdf (accessed 1 March 2018). 